\title{
0 ENSINO DE ARTEFATOS DE CONTABILIDADE GERENCIAL À LUZ DA TEORIA DA APRENDIZAGEM VIVENCIAL: ANÁLISE DA VIVÊNCIA EM UM JOGO DE EMPRESAS
}

\section{TEACHING MANAGEMENT ACCOUNTING ARTIFACTS IN THE LIGHT OF EXPERIENTIAL LEARNING THEORY: ANALYSIS OF EXPERIENCE IN A BUSINESS GAME}

Trabalho apresentado em 24 a 26 de agosto de 2018 no $29^{\circ}$ Enangrad - Encontro Nacional de Cursos de Graduação em Administração, com o título: "O Uso de um Jogo de Empresas para o ensino de Ferramentas de Gestão: Teoria e Prática em uma Empresa Simulada".

\section{RESUMO}

Aliar teoria e prática é um dos grandes desafios para o ensino em escolas de negócios. Por vezes, muitos conceitos de gestão têm complexo delineamento e difícil visualização prática, como pode ocorrer com o ensino de artefatos de contabilidade gerencial. Diante disso, jogos de empresas podem proporcionar um ambiente para a prática gerencial, sob risco e incerteza controlados, para que os estudantes possam desenvolver competências necessárias à vida profissional. Nesse sentido, o presente trabalho objetiva identificar as contribuições/limitações do uso de jogos de empresa para o ensino de artefatos de contabilidade gerencial. Trata-se de um estudo ex-post facto que analisa o desempenho de uma empresa simulada durante a vivência em um jogo de empresas. A partir de um problema gerencial e dos efeitos organizacionais visualizados na vivência proveniente da tomada de decisão dos estudantes, que assumiram o papel de diretores, os relatórios gerenciais produzidos pelo simulador e pelos estudantes foram analisados à luz do ciclo de Kolb, demonstrando assim, que há indícios de que a vivência pôde propiciar um ambiente que fomente o aprender pela ação em contabilidade gerencial.

Palavras-chave: Jogos de Empresas. Contabilidade Gerencial. Aprendizagem Vivencial.

\section{ABSTRACT}

Allying theory and practice is one of the great challenges for teaching in business schools. Many management concepts sometimes have complex delineation and difficult practical visualization, as can occur with teaching management accounting artifacts. Given this, business games can provide an environment for management practice, under controlled risk and uncertainty, so that students can develop skills necessary for working life. In this sense, the present work aims to identify the contributions / limitations of using business games for teaching management accounting artifacts. This is an ex post facto study that analyzes the performance of a simulated company during the experience of a business game. From a managerial problem and the organizational effects visualized in the student decision-making experience, which assumed the role of managers, the managerial reports produced by the simulator and the students were analyzed in the light of the Kolb cycle, thus demonstrating that there is evidence that the experience could provide an environment that fosters learning by action in management accounting.

Keywords: Business Games. Management Accounting. Experiential Learning.
Humberto Reis dos Santos-Souza É tecnólogo em Processos Gerenciais e mestre em Administração pela UFF. É professor do Instituto Federal de Educação, Ciência e Tecnologia do Rio de Janeiro Campus Resende e pesquisador no Grupo de Estudos Multidisciplinares em Tecnologia e Ciências do IFRJ e no Laboratório de Gestão Organizacional Simulada da UFF. Seus temas de pesquisa são: métodos ativos para o ensino de administração, empreendedorismo e gestão de projetos. Contato: IFRJ - Av. Pref. Botafogo, s/n Comercial, Resende - RJ, 27541-030. E-mail: humberto.souza@ifrj.edu.br

Maxwel Azevedo-Ferreira Possui Mestrado Profissional em Administração (2015) e Graduação em Administração (2012) - ambos pela Universidade Federal Fluminense (UFF). É professor do Instituto Federal de Educação, Ciência e Tecnologia do Rio de Janeiro (IFRJ) e pesquisador do Grupo de Pesquisas em Administração e Desenvolvimento (GPADES/ UFF) e do Grupo de Estudos Multidisciplinares em Tecnologia e Ciências (GEMTC/IFRJ). Tem experiência na área de Administração. Contato: IFRJ - Av. Pref. Botafogo, s/n, Comercial, Resende - RJ, 27541-030. E-mail: maxwel.ferreira@ifrj.edu.br 


\section{INTRODUÇÃO}

Os modelos convencionais de ensino em Ciências Contábeis e Administração, centrados no professor e não no estudante, apresentam algumas barreiras para o processo de aprendizagem efetiva, demonstrando pouco foco no pensamento crítico, valorização do conhecimento memorizado e a sobrevalorização da sala de aula (Paula \& Rodrigues, 2006, Sauaia, 2013).

Jogos de empresas podem apresentar potencialidades no processo de ensino-aprendizagem, especialmente quando alicerçados em teorias educacionais consistentes e quando aliados aos métodos convencionais, de modo que, os resultados da utilização de jogos de empresa para o ensino gerencial têm se mostrado satisfatórios em alguns estudos (Ben-Zvi, 2010, Apesteguia, Azmat, \& Iriberri, 2012, Silva, Oliveira \& Motta, 2013, Kriz \& Auchter, 2016).

É possível ampliar a mera participação em um jogo de empresas por meio da proposta educacional do Laboratório de Gestão que alia o simulador organizacional, o jogo de empresas e a pesquisa aplicada compondo os três pilares conceituais. No Laboratório de Gestão, o estudante vivencia o processo de tomada de decisão, sob risco e incerteza controlados, e, a partir das observações, análises e intervenções, o estudante constrói um relatório científico que descreve a utilização da teoria para resolver um problema gerencial, por exemplo. Desse modo, propicia-se um ambiente para a aprendizagem sistêmica e crítica, onde o estudante tem a oportunidade de observar as relações de causa e efeito, dentro de um ambiente controlado - um laboratório (Sauaia, 2013, Oliveira, 2017, Oliveira \& Silva, 2019).

O Laboratório de Gestão (tecnologia educacional) pode contribuir com a relação ensino-aprendizagem, pois, tem a capacidade de tornar o processo de ensino centrado na prática e com foco no aluno, facilitando o entendimento de conceitos abstratos (Oliveira, 2009). Esses conceitos abstratos geram algum nível de incerteza, que, por vezes, dificulta a aprendizagem dos estudantes, quando considerados somente os modelos convencionais de ensino (Muller, Schuster \& Zonatto, 2017). Nesse sentido, os jogos de empresas podem permitir que o estudante percorra o ciclo de aprendizagem mediado pela ação, conforme preconiza a Teoria da Aprendizagem Vivencial (Kolb \& Kolb, 2005, Oliveira \& Sauaia, 2011, Kolb, 2015, Oliveira \& Silva, 2019).

Nota-se que o ensino na área de gestão e negócios está repleto de conceitos abstratos que, por vezes, materializam-se apenas na vida profissional. Na contabilidade gerencial, por exemplo, podemos exemplificar esse dilema para o ensino nas relações entre custo/volume/lucro, em especial ao tratar da margem de contribuição e do ponto de equilíbrio. (Braga, 1989, Dias, 1992, Perez, Oliveira \& Costa, 2011).

Compreender o delineamento das estruturas de custos é fundamental para o sucesso das organizações e, em um ambiente simulado, não se faz diferente (Redivo, 2004, Hinterhuber, 2004, Ribeiro, Sauaia, \& Fouto, 2014). Nesse sentido, o presente estudo justifica-se na necessidade de utilização de método de ensino/aprendizagem voltados ao aprender por fazer, onde o estudante de Ciências Contábeis e Administração torna-se centro do processo de ensino aprendizagem e não apenas expectador.

Quando permite-se que o estudante tome decisões sob risco e incerteza, em um ambiente laboratorial controlado e com verossimilhança ao mundo real, é possível que ele desenvolva competências gerenciais, inclusive aquelas relacionadas à custos, margem e lucratividade (Oliveira, 2009, Ribeiro, Sauaia, \& Fouto, 2014, Ribeiro, Sauaia, Mello \& Torres, 2015, Oliveira, 2017).

Este estudo foi conduzido na disciplina de Laboratório de Gestão Organizacional Simulada II, oferecida para estudantes dos cursos de Ciências Contábeis e Administração em uma universidade federal localizada no sul do estado do Rio de Janeiro. Alguns estudantes do Mestrado Profissional em Administração da mesma universidade também participaram da vivência. A partir do conceito do Laboratório de Gestão, a disciplina utiliza o jogo de empresas para promover a construção de um significado dinâmico para os conhecimentos estáticos adquiridos durante o percurso de formação, ao passo que desenvolve habilidades gerenciais no processo de tomada de decisão sob risco e incerteza.

O problema de pesquisa é expresso pelo seguinte questionamento: quais as potencialidades e limitações do uso de jogos de empresa para o processo de ensino de artefatos de contabilidade gerencial? Perante o questionamento e à luz da Teoria da Aprendizagem Vivencial, objetiva-se, com este estudo, identificar as contribuições/limitações do uso de jogos de empresa para o ensino de elementos de contabilidade gerencial.

Este artigo organiza-se em uma breve fundamentação teórica seguida do método. Apresenta-se, ainda, o contexto onde a empresa simulada está inserida, bem como a análise dos dados e as considerações finais.

\section{FUNDAMENTAÇÃO TEÓRICA}

A construção do referencial teórico abarca, dentro da especificidade da pesquisa, dois pilares específicos abrangendo considerações acerca de jogos de empresa e, também, os conceitos de margem de contribuição e ponto de equilíbrio dentro do contexto da contabilidade gerencial.

\subsection{Jogos de empresas}

Jogos para o ensino e como ambiente de pesquisa são empregados por ampla gama de áreas da ciência e não só pelas escolas de negócios (Keys \& Wolfe, 1990). Um jogo de empresas pode ser definido como um método empregado 
para criar ambientes vivenciais, dentro dos quais, a aprendizagem pode ocorrer e, em que, o comportamento gerencial pode ser desenvolvido e observado. Nesse sentido, também podem ser utilizados para testagem de teorias e criação de modelos (Keys \& Wolfe, 1990, Kriz \& Hense, 2006, Oliveira, 2017).

A criação do jogo de empresas, por si, representa uma simplificação da realidade e modela uma organização, sendo que, a interação entre os elementos (que envolvem inputs, processamento e outputs), representam uma modelagem que deve coadunar com os preceitos teóricos (Keys \& Wolfe, 1990, Kriz \& Hense, 2006, Oliveira, 2009, Ben-Zvi, 2010, Sauaia, 2013, Oliveira \& Silva, 2019).

Por outro lado, a testagem de cenários e a aplicação e testagem de teorias também ocupam espaço em um jogo de empresas. Isso é importante porque a qualidade de um jogo de empresas pode ser mensurada pela capacidade de resposta que ele apresenta quando confrontado com os limites de uma teoria, por exemplo. Desse modo, o artefato deve emular uma resposta similar a que, obviamente, espera-se encontrar também no mundo real (Kleijnen \& Smits, 2003, Kolb \& Kolb, 2005, Ben-Zvi, 2010, Sauaia, \& Oliveira, 2011, Silva, Oliveira, \& Leal, 2016).

Algumas pesquisas indicam que jogos de empresas, que atendam preceitos de qualidade educacional, consigam representar ambientes com suficiente similitude ao mundo organizacional em que os executivos estão inseridos e, para além, atestam o uso para validação teórica, desde que, respeitado o rigor metodológico necessário. Além disso, a validade educacional dos jogos de empresas, como já expresso, respeitadas as especificações relacionadas à qualidade, também tem sido apoiada pelos mesmos estudos (Beal, Cohen, Burke, \& McLendon, 2003, Kleijnen \& Smits, 2003, Kolb \& Kolb, 2005, Kriz \& Hense, 2006, Oliveira, 2009, Ben-Zvi, 2010, Stainton, Johnson \& Borodzicz, 2010, Sauaia, \& Oliveira, 2011, Sauaia, 2013, Ben-Zvi, \& Carton, 2014, Kallás \& Sauaia, 2014, Kolb, Kolb, Passarelli, \& Sharma, 2014, Silva, Oliveira, \& Leal, 2016, Oliveira \& Silva, 2019).

Nesse contexto, é importante destacar o papel da Teoria da Aprendizagem Vivencial (Experiential Learning Theory-ELT), que é baseada no trabalho de David Kolb sob influência de vários teóricos da educação, tais como Piaget e Freire. Para o jogo de empresas, a ELT figura-se como uma das teorias educacionais que sustentam o processo de ensino-aprendizagem. Para Kolb, o conhecimento é criado por meio da transformação da experiência, sendo que, a simples percepção da experiência não é suficiente para proporcionar a aprendizagem. O ciclo da aprendizagem vivencial (Figura 1), apresenta dimensões estruturais do processo de aprendizagem dispostas em um ciclo (Kolb \& Kolb, 2005, Oliveira \& Sauaia, 2011, Kolb, 2015).

Para tornar a explicação didática, em tratando-se da experiência e sua transformação, o ciclo apresenta a experiência concreta, que está relacionada à experiência sensorial que, por sua vez, permite interpretar e identificar o que está acontecendo, ao passo que o aprendiz envolve-se na vivência. Já a observação reflexiva engloba a criação de significado para um problema com base no que a memória já tem em registro, o que compreende, evidentemente, a reflexão. A conceitualização abstrata, outra etapa do ciclo de Kolb, envolve a teorização, ou o entendimento geral de como determinado evento ocorre, sendo que, em situações similares, utiliza-se uma sequência de ações conhecidas para resolver determinado problema ou atingir determinado objetivo. Já a experimentação ativa abarca a ação, ou seja, a transformação da experimentação sensorial para uma experiência mediada pela atividade, uma vez que, a experiência sensorial permitiu a absorção da informação e a experimentação ativa permite a transformação da informação em ação para um determinado fim (Kolb \& Kolb, 2005, Oliveira \& Sauaia, 2011, Kolb, 2015).

Figura 1. Ciclo da Aprendizagem Vivencial de David Kolb

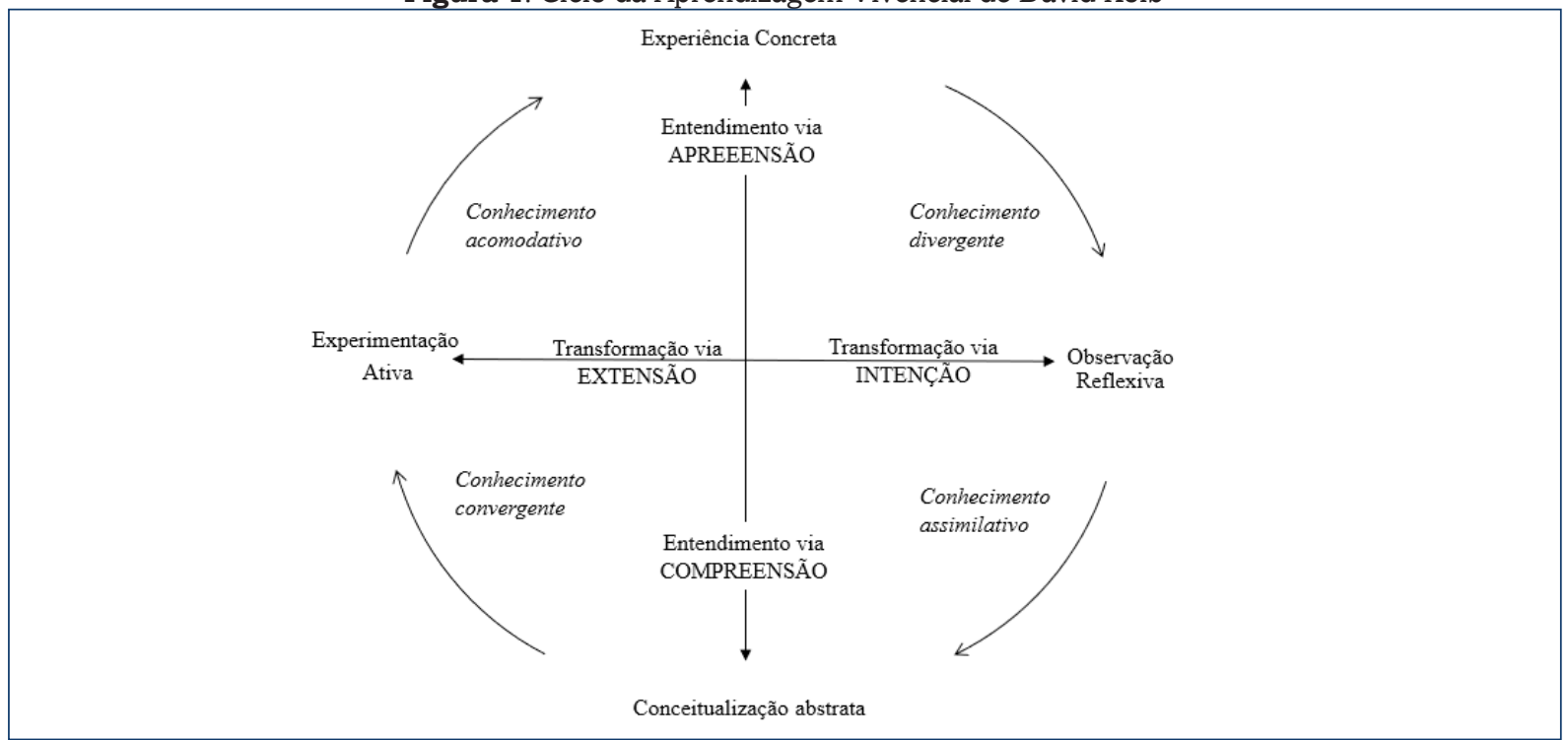

Fonte: Adaptado de Kolb (2015 p.168). 
Diante dessa teoria, a validade educacional é demasiadamente importante, uma vez que, os jogos de empresas vêm sendo utilizados há bem mais de meio século em escolas de negócios (Keys \& Wolfe, 1990, Faria, Hutchinson, Wellington, \& Gold, 2009). Como proposta pedagógica para o ensino-aprendizagem, faz parte do tripé conceitual que sustenta o Laboratório de Gestão, que por sua vez, abrange o simulador organizacional, o jogo e a pesquisa aplicada (Sauaia, 2013, Oliveira \& Silva, 2019).

O simulador compreende o artefato que emulará uma organização, sendo o componente tangível pelo qual a situação da empresa é definida e de onde emanam as regras econômicas e os dados processados para a tomada de decisão. $\mathrm{O}$ jogo de empresa compreende o elemento intangível, que abrange o processo de tomada de decisão sob risco e incerteza controlados e, consequentemente, a análise dos resultados. A pesquisa aplicada é conduzida pelo participante em seu papel gerencial, de modo a elaborar um relatório que expresse um problema organizacional analisado à luz de um referencial teórico. $\mathrm{O}$ encadeamento harmônico desses três elementos pode produzir a aprendizagem significativa, por meio da ação, pautada nas dimensões do ciclo da aprendizagem vivencial (Sauaia, 2013, Oliveira \& Silva, 2019).

Cabe ressaltar que o Laboratório de Gestão não preconiza o jogo pelo jogo, mas que o ciclo da aprendizagem tem sua completude quando, de posse de um problema organizacional, o estudante tem a possibilidade de testar cenários e desenhar uma solução pautada em uma teoria organizacional consolidada (Oliveira \& Sauaia, 2011, Sauaia, 2013, Oliveira, 2017, Oliveira \& Silva, 2019). Assim, diante dessas contribuições e do objetivo deste trabalho, há que se considerar alguns conceitos relacionados à contabilidade gerencial e seus respectivos processos de ensino.

\subsection{O Ensino de Contabilidade Gerencial}

O ensino de contabilidade gerencial, em especial a sua relação com o ambiente de prática, é relevante, pois, há que se pensar para além dos registros contábeis, dado o papel estratégico que a contabilidade gerencial ocupa (Horngren, 2000, Cruz, Coutinho, Lagioia, Morais, Peixoto \& Meireles, 2014, Beuren, Souza, \& Feuser, 2017; Lavarda, Panucci-Filho \& Michels, 2017). No entanto, ainda existem algumas lacunas no ensino de contabilidade gerencial com especial foco à necessidade de articulação entre teoria e prática e adequações curriculares (Miranda, Riccio \& Miranda, 2013, Faria \& Leal, 2016, Muller, Schuster \& Zonatto, 2017). Dada a extensão do tema e o escopo do artigo, apenas alguns elementos de contabilidade gerencial serão abordados na próxima seção. Para tanto, foram escolhidos elementos classificados como "tradicionais" na pesquisa de Oliveira, Marques e Cintra (2019), sobre a evolução dos artefatos de contabilidade gerencial.

\subsubsection{As Relações de Custo/Volume/Lucro em um Jogo de Empresas}

A correta compreensão das relações custo/volume/lucro pode auxiliar no processo de tomada de decisão, ao passo que, o esquema de análise pode permitir a avaliação primeira do desempenho geral, bem como, tornar-se um instrumento de planejamento para os gestores (Horngren, 2000; Miaguchi \& Sauaia, 2013, Hernandes Jr., 2016). Para tanto, há que se compreender dois conceitos fundamentais para essa análise, a saber: margem de contribuição e ponto de equilíbrio.

A margem de contribuição representa a parcela remanescente da receita de venda após subtraídos os custos e despesas variáveis totais, ou seja, no quanto cada unidade vendida contribui para cobrir o total do custo e da despesa fixa (Braga, 1989, Dias, 1992, Horngren, 2000).

O ponto de equilíbrio, por sua vez, permite entender como o lucro pode ser influenciado pelas variações dos componentes que integram as receitas de vendas e os custos. Engloba a quantidade vendida, seus respectivos preços, além dos custos e despesas variáveis e fixas. Essa ferramenta permite acompanhar a evolução da margem de contribuição e propicia informações sobre a saúde financeira da empresa (Braga, 1989, Dias, 1992, Miaguchi \& Sauaia, 2013). Em linhas gerais, compreende "o nível de vendas no qual a receita se iguala as despesas e o lucro é zero" (Horngren, Sundem \& Stratton, 2004, p. 40).

A análise de ponto de equilíbrio, também conhecida como break-even point, é um componente da relação custo/ volume/lucro - CVL (Cost/Volume/Profit - CVP), assim como a margem de contribuição (Hinterhuber, 2004, Horngren, Sundem \& Stratton, 2004, Ferreira, Wanzeler, Melo, Oliveira, \& Oliveira, 2014). Embora o ponto de equilíbrio apresente algumas limitações, pode ser utilizado pelas organizações para monitoramento e apoio na tomada de decisões, planejamento, melhoria dos controles, construção do preço, análise de viabilidade, gestão estratégica de custos, bem como, para o fornecimento de informações para o gestor, mercado e investidores (Hinterhuber, 2004, Santos, Marion \& Kettle, 2014, Almada, Souza \& Laia, 2016, Fuksa, Trzaskuś-Żak, Gałaś, \& Utrata, 2017). Como potencialidades, a utilização do ponto de equilíbrio pode auxiliar na análise de viabilidade, avaliação de desempenho e visualização gráfica dos resultados potenciais (Horngren, Sundem \& Stratton, 2004, Wernke \& Lembeck, 2011).

Para o ensino desses conceitos (margem de contribuição e ponto de equilíbrio) em sala de aula há que se considerar uma gama de desafios, envolvendo a relação teoria e prática, construção de ementas e o material didático, por exemplo, (Santos, 2003, Oliveira \& Sauaia 2011, Miranda, Riccio \& Miranda, 2013, Muller, Schuster \& Zonatto, 2017). Em se tratando da delimitação dos custos e do apreçamento, as decisões sob risco e incerteza permeiam o processo educacional envolvendo o método do jogo de empresas, bem como, na vida organizacional. De um lado, temos os riscos na tomada de decisão relacionados com prejuízos cada vez maiores, assim como, às oportunidades relacionadas a lucros crescentes. Sendo assim, entender o processo de precificação, atrelado ao estudo do processo de delimitação de custos é fundamental para a gestão empresarial (Braga, 1989, Oliveira, 2009, Miaguchi \& Sauaia, 2013, Sauaia, 2013). 
No entanto, embora o conteúdo teórico seja muito bem elucidado nas disciplinas de contabilidade gerencial, resta uma lacuna entre a teoria e a prática que pode ser preenchida pelos jogos de empresas. Como auxiliar no processo de ensino-aprendizagem, jogos de empresa podem apresentar uma alternativa para a educação gerencial efetiva em custos, por exemplo, (Sauaia, 2013, Ribeiro, Sauaia, \& Fouto, 2014, Ribeiro et al.,2015), sendo que, as próximas seções dedicam-se à apresentação dessa alternativa em um ambiente simulado.

\section{MÉTODO}

A orientação metodológica do trabalho tem abordagem qualitativa, de natureza aplicada e, quanto aos objetivos tem caráter exploratório-descritivo, pois, visa a aproximação e a descrição de determinado fenômeno (Gerhardt \& Silveira, 2009). O percurso metodológico pode ser observado na Figura 2. Quanto aos procedimentos técnicos, trata-se de um estudo ex-post facto, que analisou os resultados de um grupo submetido a um quase-experimento com jogos de empresas. A pesquisa ex-post facto permite a análise desse tipo, uma vez que, não há a possibilidade de manipulação das variáveis e os resultados da vivência já havia demonstrado seus efeitos ao longo do tempo (Silva \& Menezes, 2005, Vergara, 2009, Cooper \& Schindler, 2011).

Por sua vez, um quase-experimento consiste em um delineamento de pesquisa que, por implicações do campo, não apresenta distribuição aleatória dos sujeitos do corpus, nem tampouco um grupo de controle ou pré e pós-testes. Embora o quase-experimento não permita o total controle, é possível observar o que, como e com quem ocorre determinado fenômeno (Malhotra, 2001; Cooper \& Schindler, 2011). Assim sendo, este estudo trata-se de um quase-experimento de série temporal única, composto de um bimestre de estudos, que representou um período simulado de dois anos.

O quase-experimento em questão ocorreu na disciplina de Laboratório de Gestão Organizacional Simulada II, do curso de Ciências Contábeis e Administração, em uma instituição federal de ensino superior, na região do Médio-Paraíba, no estado do Rio de Janeiro. Ao todo participaram da vivência 36 estudantes que compuseram seis empresas simuladas.

O simulador escolhido para a geração do ambiente laboratorial em estudo foi o Shadow Manager. A partir dele foi criado o ambiente simulado denominado Simulação GregoMIX (SGM), onde ocorreu o jogo de empresas. O SGM ilustra, com similitude adequada ao aprendizado, a dinâmica do setor de produtos eletrônicos, especialmente as relações entre indústrias e atacado (Oliveira \& Silva, 2019). 
Figura 2 - Mapa do Método

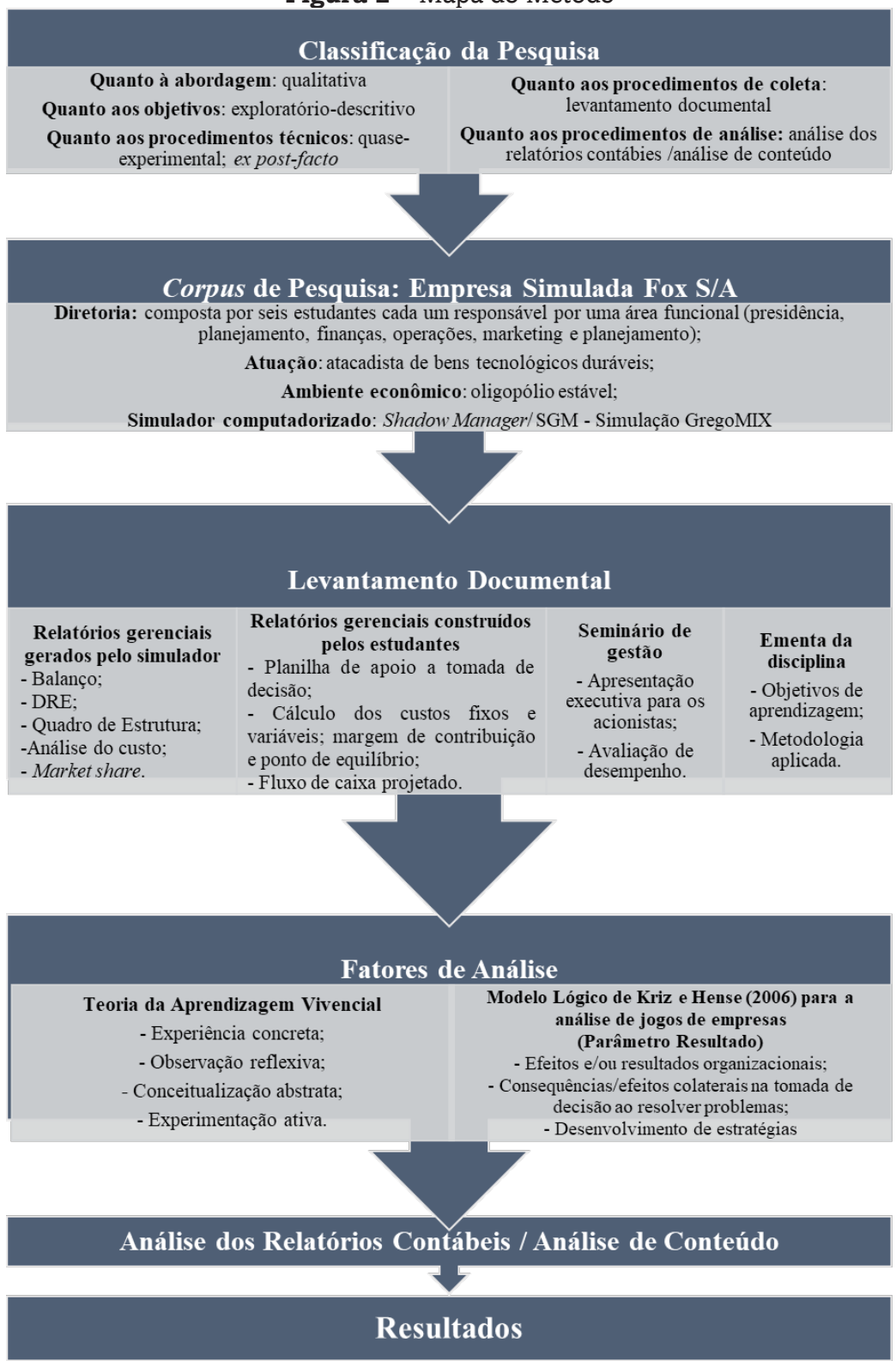

Fonte: adaptado de Kriz \& Hense, 2006, Gerhardt \& Silveira, 2009, Cooper \& Schindler, 2011, Kolb, 2015.

O simulador gera os resultados a partir do processo de tomada de decisão das empresas/equipes. Esses resultados são expressos em relatórios gerenciais utilizados como base para novos processos de tomada de decisão. Cabe destacar que o SGM promove a interação entre as equipes/empresas no processo de negociação entre empresas industriais e atacadistas criando uma cadeia, por isso caracteriza-se como um ambiente dinâmico (Oliveira \& Silva, 2019).

Para este estudo, escolheu-se apenas uma das empresas simuladas por limitações metodológicas e por resultados organizacionais expressivos da referida organização durante o jogo de empresas, em especial, no uso de elementos de contabilidade gerencial para embasar o processo de tomada de decisão e elaboração de estratégias.

Como instrumento de coleta utilizou-se o levantamento documental. Por tratarem-se de equipes heterogêneas e pelo papel de um dos pesquisadores da vivência (observação participante) optou-se pela análise documental para evitar que os resultados fossem carregados de impressões e sofressem algum tipo de influência.

Os documentos levantados pela vivência, foram constituídos principalmente dos documentos originários do simulador, traduzidos em relatórios contábeis/financeiros, tais como: quadro da estrutura de custos, balanço patrimonial, DRE, análise de custo, market share, formulário de tomada de decisão, dentre outros.

Durante a vivência, os estudantes também construíram seus relatórios gerenciais a partir das necessidades e dos problemas que emergiram durante o jogo de empresas. Dentre os documentos criados pelos estudantes e alinhados ao 
escopo do trabalho destacam-se: a planilha de apoio a tomada de decisão, o cálculo dos custos fixos e variáveis, os cálculos de margem de contribuição e ponto de equilíbrio, e, o fluxo de caixa projetado.

Paralelo a esses documentos, foram utilizados os relatórios provenientes do seminário de gestão, onde os estudantes apresentam para toda a classe os resultados organizacionais provenientes da vivência. A ementa da disciplina também foi considerada para a verificação dos resultados à luz do método utilizado e dos objetivos a serem alcançados durante o jogo de empresas.

Os relatórios contábeis/financeiros foram analisados qualitativamente a partir das relações de causa e efeito observadas durante o exercício contábil em análise. Paralelo a isso, os relatórios gerados pelos estudantes foram analisados por análise de conteúdo, tendo como base os parâmetros do ciclo de Kolb (2015) já descrito na literatura, obedecendo os preceitos de Bardin (2013).

Adjacentemente foram incluídos o parâmetro resultado do modelo lógico de Kriz e Hense (2006) que foi especialmente desenhado para avaliar a aplicabilidade de um jogo de empresas. Em um amplo estudo, esses autores descrevem os parâmetros para avaliação de jogos de empresas considerando três parâmetros centrais envolvendo entradas, processamentos e resultados. Para este estudo, em razão da natureza dos dados, optou-se pela utilização do parâmetro "resultado" em termos de efeitos e/ou resultados organizacionais, consequências/efeitos colaterais na tomada de decisão ao resolver problemas e ao desenvolver estratégias. Por conseguinte, as análises interligam os efeitos da vivência com o ensino/prática de artefatos de contabilidade gerencial a partir dos resultados organizacionais da empresa simulada gerenciada por estudantes.

\section{ANÁLISE DOS RESULTADOS}

\subsection{Contexto do Quase-Experimento e Situação Problema}

A Fox S/A é uma empresa simulada do ramo atacadista de bens tecnológicos duráveis. A empresa comercializa quatro produtos distintos, denominados Alpha, Beta, Ômega e Iphanton, cada um com vantagens e custos diferentes. Esses produtos empregam a tecnologia para ajudar nas tarefas corriqueiras tais como comunicação por voz, vídeo e/ ou mensagem, calculadora, agenda eletrônica, acesso à internet, dentre outros. O ambiente econômico oligopolista em que a empresa está inserida é estável. Além desses fatores, outras empresas simuladas estão presentes nesse ambiente, caracterizado por organizações industriais e atacadistas, formando concorrência e/ou uma cadeia entre os agentes econômicos (Laboratório de Gestão Organizacional Simulada, 2017, Oliveira \& Silva, 2019).

A empresa simulada possui seis áreas funcionais, a saber: presidência, planejamento, finanças, operações, marketing e planejamento. Cada área funcional é de responsabilidade de um estudante, que necessariamente precisa tomar decisões sob risco e incerteza. Assim, a empresa foi composta por 4 estudantes da graduação e 2 estudantes da pós-graduação. A empresa começa suas operações com $\mathrm{R} \$ 500.000,00$ iniciais e durante a simulação precisa otimizar os lucros e remunerar adequadamente os acionistas (Laboratório de Gestão Organizacional Simulada, 2017, Oliveira \& Silva, 2019).

Figura 3 - Evolução da Margem de Contribuição e Influência Sobre os Resultados no Período Simulado de 2016

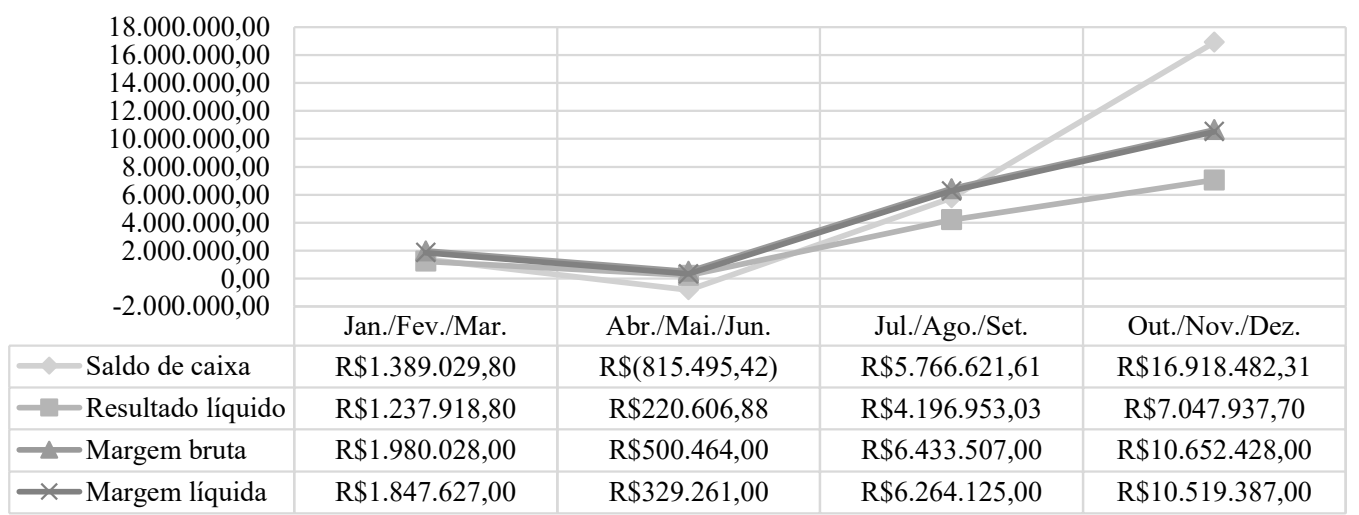

Fonte: dados da pesquisa, 2019.

Além disso, o ambiente econômico simulado exige que a empresa simulada atacadista negocie diretamente com a indústria os produtos que deseja comercializar, estabelecendo, assim, preços e prazos razoáveis que maximizem a vantagem competitiva da empresa. Essa relação ocorre por negociação direta com os estudantes/executivos de indústrias simuladas, formando uma rede de relacionamento. As relações fornecedores-indústria e atacado-varejo são randomizadas pelo simulador computadorizado denominado Grego Mix (Laboratório de Gestão Organizacional Simulada, 2017, Oliveira \& Silva, 2019). 
Nesse contexto, durante a segunda rodada da simulação, compreendendo o período simulado entre abril e junho de 2016, houve um erro na precificação, especialmente na determinação da margem de contribuição (Figura 3). Embora a margem de contribuição total tenha sido positiva e suficientemente adequada para cobrir os custos e despesas fixos, ocasionou o estouro de caixa conforme pode ser observado na Tabela 1, assim como, prejudicou o resultado financeiro da empresa, como pode ser observado na Figura 3.

Ainda que os conceitos fundamentais para a delimitação dos custos fossem de conhecimento de alguns membros da equipe dada a construção curricular dos cursos de Ciências Contábeis e Administração, o fato passou despercebido, ocasionando prejuízos para a organização simulada. De fato, o ensino convencional de custos, nas escolas de gestão, pode apresentar algumas deficiências (Muller, Schuster \& Zonatto, 2017). Dessa maneira, os resultados demonstram indícios de que a empresa em estudo não possuía uma ideia clara da origem de seus resultados, nem quando a mesma começaria a gerar lucro ou prejuízo. De todo modo, para as organizações os efeitos da gestão de custos podem tomar proporções significativas nos resultados organizacionais como ocorreu neste quase-experimento em análise (Redivo, 2004, Hinterhuber, 2004, Ribeiro, Sauaia, \& Fouto, 2014).

Nesse panorama, de posse dos dados da empresa, a equipe de gestores/estudantes passou a analisar alternativas para reverter a situação negativa que atingiu a empresa no segundo período de existência, valendo-se de relatórios financeiros e contábeis oferecidos pelo simulador, bem como, de apoio teórico.

Com base nos relatórios os estudantes passaram à construção do fluxo de caixa do período simulado de abril a junho de 2016, que está disposto na Tabela 1. Nele pode-se observar que a margem de contribuição afetou diretamente os resultados da empresa, especialmente o seu caixa. Ainda assim, observou-se que a margem de contribuição unitária, atingiu o seguinte patamar para cada produto: Beta $\mathrm{R} \$ 58,43$, Ômega $\mathrm{R} \$ 16,39$ (dados extraídos dos relatórios gerenciais). A relação perde-ganha, com um fornecedor industrial, também influenciou a decisão da empresa por manter margens tão pequenas, conforme pôde ser observado no formulário de tomada de decisão da rodada anterior. Nesse sentido, os custos e despesas fixos, representado em grande parte pelos gastos administrativos das operações e estoques, não foram cobertos pela margem de contribuição. Embora o faturamento tenha subido 148,03\% nos três primeiros trimestres, o resultado líquido despencou no segundo trimestre, representando -82,18\% em comparação com o período anterior. No entanto, o que sustentou a saúde financeira da empresa no período foi a política de contas a receber e a pagar, o próprio aumento no faturamento em $60,02 \%$ de abril até setembro e empréstimos.

Tabela 1 - Fluxo de Caixa em Reais do Período Simulado 2016

\begin{tabular}{|c|c|c|c|c|}
\hline & jan./Fev./Mar & Abr./Mai./Jun. & jul./Ago./Set. & out./Nov./Dez. \\
\hline \multicolumn{5}{|l|}{ Receitas } \\
\hline Vendas & $5.171 .111,00$ & $12.409 .372,00$ & $18.945 .467,00$ & $40.254 .287,00$ \\
\hline Duplicatas a receber & & $1.988 .889,00$ & $5.349 .528,00$ & $9.472 .733,00$ \\
\hline Receitas Financeiras & $6.250,00$ & $28.109,00$ & $1.202,00$ & $121.874,00$ \\
\hline Saldo anterior & $500.000,00$ & $1.389 .029,80$ & $-815.495,42$ & $5.766 .621,61$ \\
\hline Total & $5.677 .361,00$ & $15.815 .399,80$ & $23.480 .701,58$ & $55.615 .515,61$ \\
\hline \multicolumn{5}{|l|}{ Despesas } \\
\hline Gastos administrativos & $129.275,00$ & $146.222,00$ & $141.625,00$ & $136.316,00$ \\
\hline Fornecedores & $3.280 .000,00$ & $14.084 .234,00$ & $5.583 .334,00$ & $23.015 .000,00$ \\
\hline Duplicatas a pagar & & $1.640 .000,00$ & $8.833 .066,00$ & $9.416 .666,00$ \\
\hline Mão de obra & $13.160,00$ & $30.119,00$ & $40.418,00$ & $82.642,00$ \\
\hline Marketing & $32.000,00$ & $80.000,00$ & $150.000,00$ & $645.000,00$ \\
\hline Logística & $214.800,00$ & $532.767,00$ & $852.546,00$ & $1.811 .443,00$ \\
\hline Empréstimos & $9.375,00$ & $8.906,00$ & $45.935,00$ & $118.594,00$ \\
\hline Impostos & $609.721,20$ & $108.647,22$ & $2.067 .155,97$ & $3.471 .372,30$ \\
\hline Total & $4.288 .331,20$ & $16.630 .895,22$ & $17.714 .079,97$ & $38.697 .033,30$ \\
\hline Saldo & $1.389 .029,80$ & - 815.495,42 & $5.766 .621,61$ & $16.918 .482,31$ \\
\hline
\end{tabular}

Fonte: relatório elaborado pelos gerentes/estudantes da empresa simulada, 2019. 
Assim, a partir das análises dos relatórios do simulador e dos relatórios gerados pelos estudantes, o diagnóstico foi estabelecido como sendo o cometimento de equívocos na definição das margens de contribuição unitárias que, embora tenham coberto parte dos custos fixos, prejudicaram os resultados da empresa.

Partindo do diagnóstico dos problemas da empresa simulada, analisaram-se os documentos que indicavam o processo de mudança ou adaptação de estratégias, como delimitado no método. Desse modo, a análise do ponto de equilíbrio realizada pelos participantes indicou que o produto ômega operava em prejuízo, embora com margem positiva, sendo que, foram vendidas 3332 unidades, ao invés de 4027 unidades necessárias para o lucro zero, conforme demonstrado na Figura 4. O produto Beta estava gerando lucro, mas abaixo do esperado para cobrir o fluxo de caixa (Tabela 1).

Figura 4 - Ponto de equilíbrio operacional do produto Ômega.

\begin{tabular}{|c|c|}
\hline Ponto de equilibrio operacional $(\mathrm{PEO})=$ & Margem de contribuição unitária \\
\hline PEO - Produto Ômega $=\frac{66000}{16,39}$ & $=4.027$ unidades \\
\hline
\end{tabular}

Fonte: construído pelos estudantes com base em Braga (1989) e Horngren (2000).

Na Tabela 1 apresenta-se os gastos fixos expressos como gastos administrativos. Em volume de vendas, a margem líquida gerada para o período simulado (abril até junho de 2016) proporcionou um resultado líquido de $\mathrm{R} \$ 329.261,00$ (Figura 3), no entanto, não foi suficiente para cobrir o caixa, que apresentava valores de contas a pagar maiores que os valores das contas a receber no período, prejudicando o fluxo de caixa. Note-se que os valores dos empréstimos dos períodos subsequentes refletem os gastos com juros, para a cobertura emergencial do caixa (Tabela 1), gerados pelo erro na delimitação da margem de contribuição unitária.

Com base na construção do fluxo de caixa (realizado pelos estudantes) para o período de abril a junho de 2016, foi possível dimensionar o desafio. Além disso, o relatório do quadro da estrutura, fornecido pelo simulador, indicou uma queda no índice de qualidade de 106,17\% no período anterior (jan./fev./mar.) para 90,84\% no período em tela, o que indica que a má gestão de custos afetou outros setores da empresa.

Figura 5 - Evolução da Margem de Contribuição por Produto Comercializado.

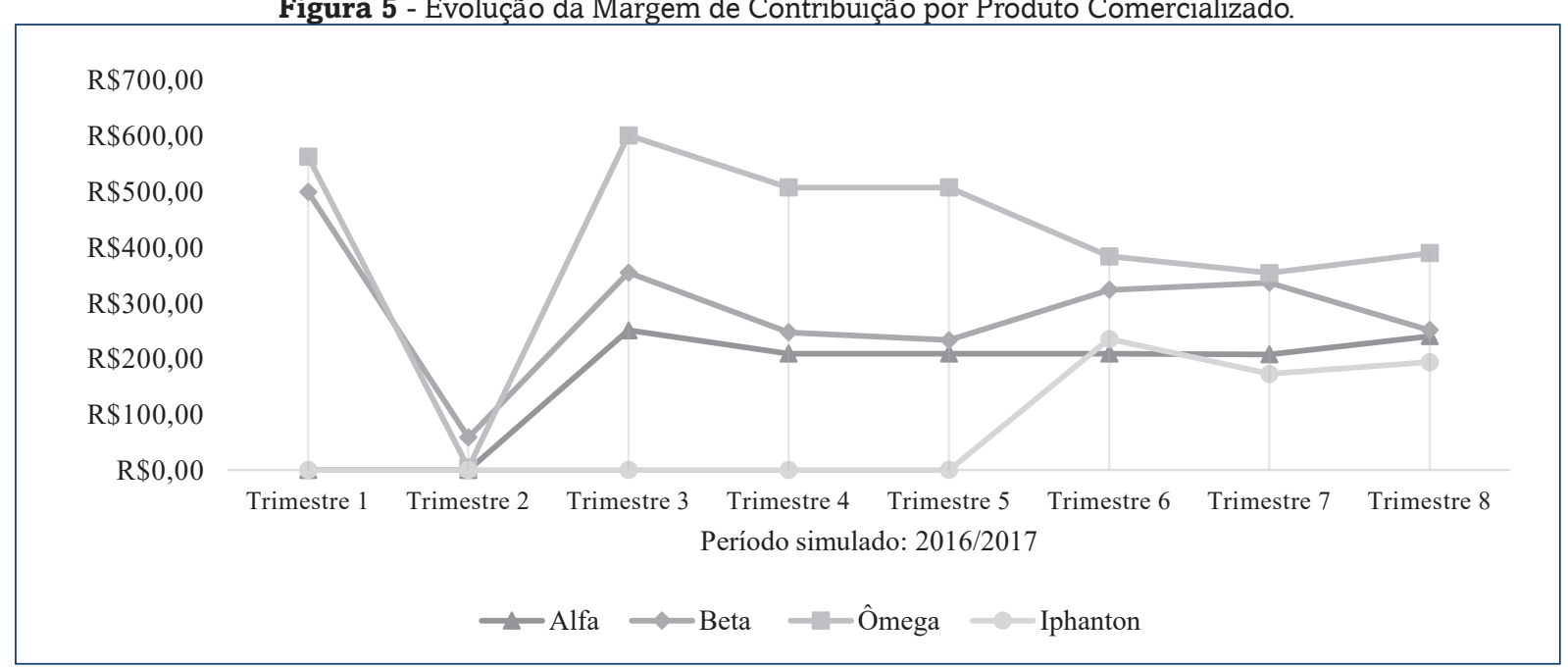

Fonte: dados da pesquisa, 2019.

Conforme os relatórios, observou-se uma mudança no processo de precificação e os resultados financeiros apresentaram consubstancial melhora, como pode ser observado na Figura 5. Sendo assim, a análise permitiu inferir que a intervenção organizacional realizada pelos estudantes a partir da situação problema proporcionou melhoria no desempenho e nos resultados da empresa em termos da evolução da margem de contribuição, faturamento, lucro líquido e participação no mercado. Isso é perceptível especialmente quando considera-se que não havia controle dos resultados da empresa e não conhecia-se o ponto de início de prejuízos e lucros, até a terceira rodada do período simulado de 2016 , conforme documentos levantados. A ação dos estudantes, coaduna-se com os efeitos organizacionais positivos apontados na teoria sobre a correta política de precificação e adequação das relações custo/volume/lucro (Horngren, 2000, Miaguchi \& Sauaia, 2013, Ferreira et al.,2014; Santos, Marion \& Kettle, 2014, Ribeiro et al.,2015, Hernandes Jr., 2016, Almada, Souza \& Laia, 2016, Fuksa et al., 2017). 
Figura 6 - Evolução do Faturamento e do Lucro Líquido por Trimestre.

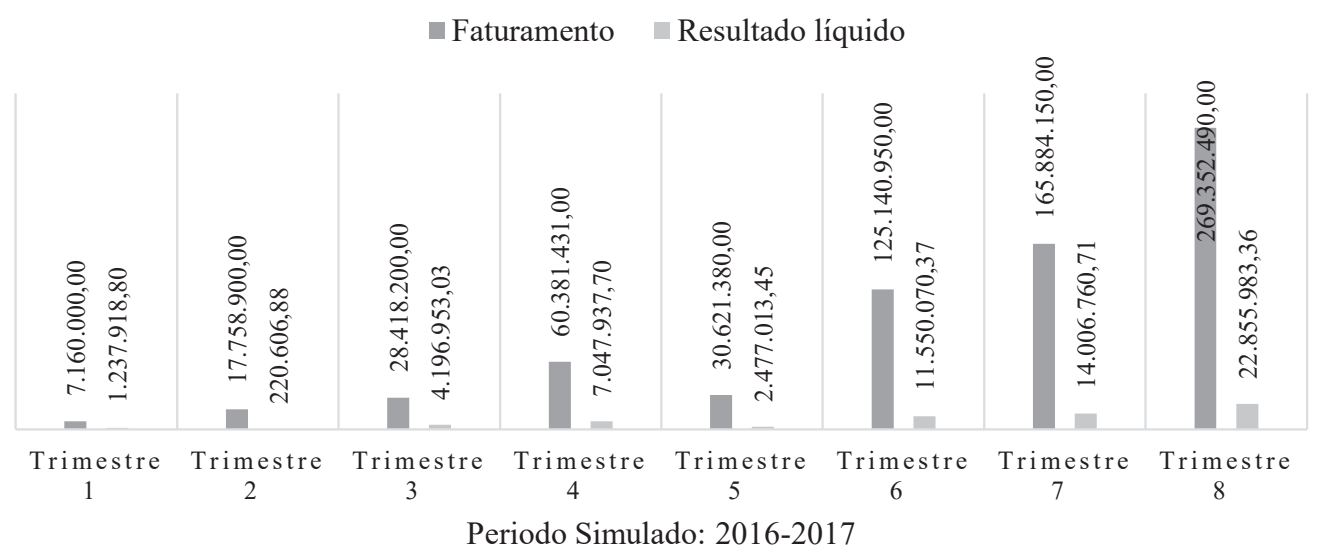

Fonte: dados da pesquisa.

Não só relativos à margem de contribuição, os efeitos puderam ser observados na evolução do faturamento e do lucro líquido, expresso na Figura 6. Em relação à posição de mercado, a Figura 7 mostra que a empresa liderou o mercado em três dos quatro produtos comercializados. Evidentemente que o correto delineamento da política de apreçamento, levando em consideração o fluxo de caixa, a margem de contribuição adequada e o ponto de equilíbrio, foram importantes para o desempenho da organização a ponto de haver modificação na estratégia quando decidiu-se comercializar um novo produto (Braga, 1989, Dias, 1992, Horngren, 2000, Miaguchi \& Sauaia, 2013, Ferreira et al.,2014; Santos, Marion \& Kettle, 2014, Ribeiro et al.,2015, Hernandes Jr., 2016, Almada, Souza \& Laia, 2016, Fuksa et al., 2017, Oliveira, Marques \& Cintra, 2019).

Figura 7 - Participação no Mercado (de outubro a novembro de 2017).

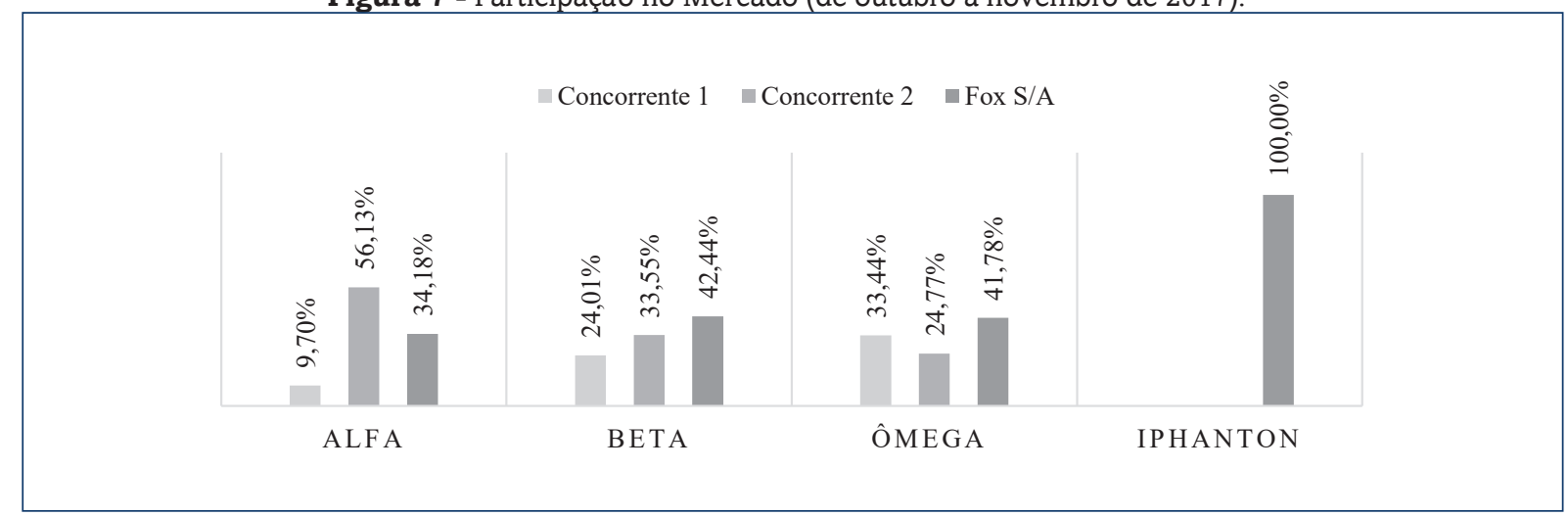

Fonte: dados da pesquisa.

\subsection{Percurso Educacional Realizado Pelos Participantes da Vivência}

Ao tomar de base o ciclo da aprendizagem vivencial de Kolb (2015) e os relatórios gerados pelo simulador e os documentos gerados pelos estudantes, pode-se observar alguns indícios da completude do processo materializado na resolução do problema organizacional apresentado na subseção anterior. A síntese dos achados da análise de conteúdo envolvendo a Teoria da Aprendizagem Vivencial encontra-se na Figura 8. 
Figura 8 - Síntese dos Resultados Segundo o Ciclo de Kolb (2015)

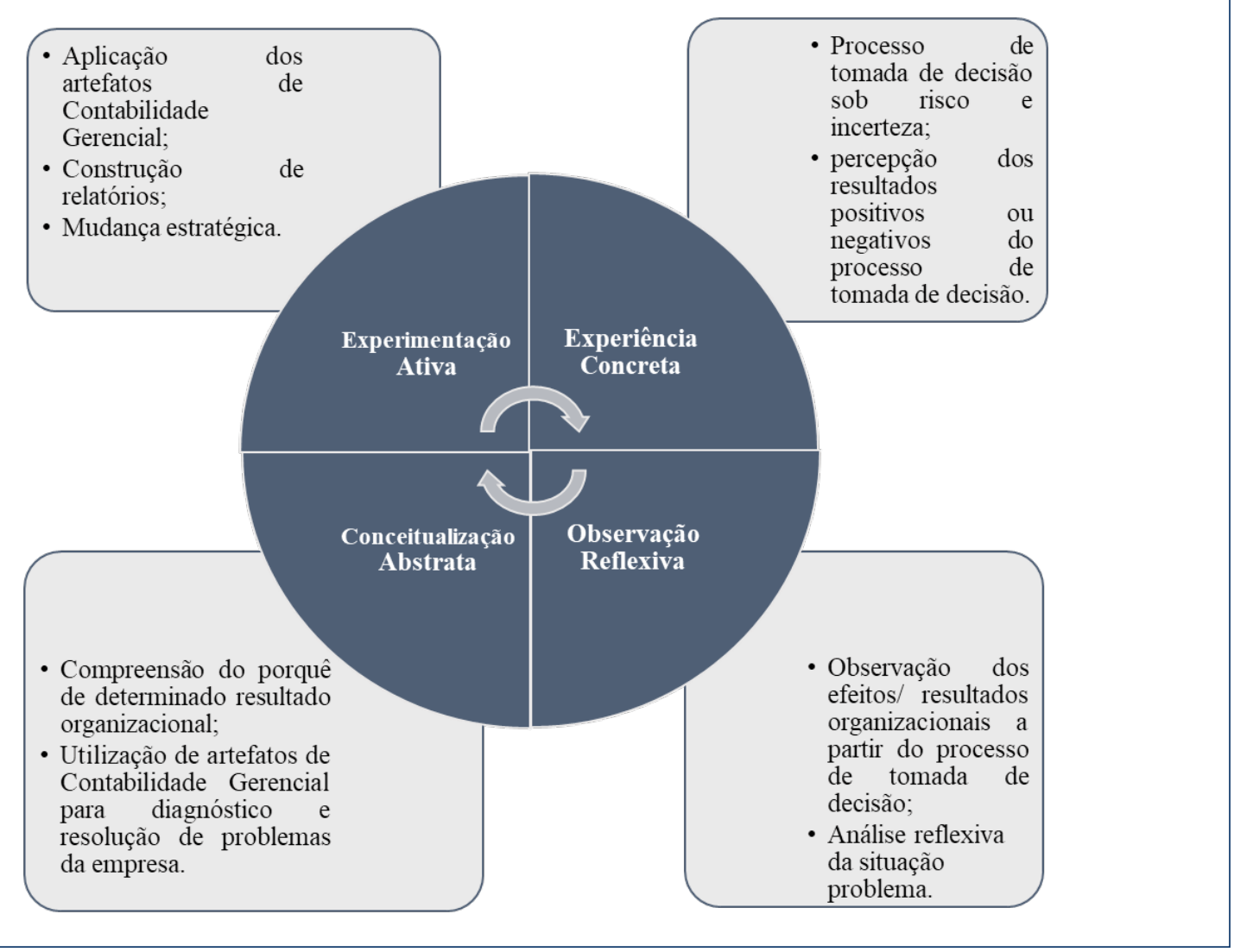

Fonte: dados da pesquisa, 2019.

Sendo assim, a partir da análise de conteúdo, passamos à exposição ponto a ponto, com início na (1) experiência concreta, onde os estudantes/executivos da empresa Fox S/A., passaram a interpretar e identificar o processo de gerenciar uma organização a partir do processo de tomada de decisão. Esse processo foi explorado por meio da análise dos relatórios específicos preenchidos pelos estudantes durante cada rodada. Essa análise permitiu identificar que os participantes da vivência experienciavam o risco e a incerteza dentro do ambiente simulado, ao passo que buscavam insumos para desenhar suas estratégias (Kolb \& Kolb, 2005, Sauaia, 2013, Kolb et al., 2014, Kolb, 2015; Oliveira \& Silva, 2019).

Na sequência, a (2) observação reflexiva, trouxe aos membros da empresa a oportunidade de observar e refletir sobre os resultados. Essa análise reflexiva, já no segundo período do jogo (abril a junho de 2016), os permitiu entender que era necessário adotar medidas para corrigir os desvios apresentados pelos resultados negativos, entendendo suas causas e efeitos. Esses resultados negativos podem ser observados na Tabela 1 - fluxo de caixa (artefato) construído pelos estudantes com base nos seus próprios conhecimentos. Nesse caso, para a análise, tomou-se de base os relatórios fornecidos pelo simulador e os documentos gerados pelos estudantes, como seus controles internos, formulários de tomada de decisão e planilhas de apoio. Em suma, as análises indicam que os estudantes puderam perceber os efeitos do processo de tomada de decisão analisando as relações e desvios entre o planejado e o realizado - comparando-se os resultados da rodada com o formulário de tomada de decisão da rodada anterior (Kolb \& Kolb, 2005, Oliveira \& Sauaia, 2011, Sauaia, 2013, Kolb et al., 2014, Kolb, 2015, Oliveira \& Silva, 2019).

A (3) conceitualização abstrata permitiu ao grupo realizar uma revisão conceitual, compreendendo a teoria que rege o processo ou, em termos práticos, o porquê do saldo de caixa negativo mesmo operando com margens de contribuição positivas. A primeira revisão conceitual foi realizada com base nos fundamentos de fluxo de caixa, em que foi possível dimensionar o tamanho do problema para a organização. A luz da teoria, os conceitos de custos, margem de contribuição e ponto de equilíbrio também emergiram como ferramentas possíveis para a resolução do problema. Os dados que subsidiam essa percepção são apresentados na Figura 4 e na Tabela 1. O que pôde-se perceber, em termos gerais, é que os estudantes manipularam o conhecimento existente sobre o tema com foco no diagnóstico e na resolução de um problema específico. Como descrito na seção anterior, esses elementos já indicam a busca da compreensão do porquê de determinado resultado, bem como, a utilização de artefatos de contabilidade gerencial para a solução do problema organizacional (Figura 8) (Braga, 1989, Dias, 1992, Kolb \& Kolb, 2005, Oliveira \& Sauaia, 2011, Sauaia, 2013, Ferreira et al.,2014, Kolb et al., 2014, Santos, Marion \& Kettle, 2014, Kolb, 2015, Ribeiro et al.,2015, Hernandes Jr., 2016, Almada, Souza \& Laia, 2016, Fuksa et al., 2017, Oliveira \& Silva, 2019). 
A (4) experimentação ativa envolve ação, ou seja, a transformação da experimentação sensorial para a experimentação ativa e a transformação da informação em ação. Nesse caso, a aplicação das tecnologias de gestão, já consolidadas em artefatos da contabilidade gerencial, permitiu à empresa uma revisão sistemática no seu plano de gestão em face dos desvios, negociando novos preços de compra e estabelecendo novos preços de venda, bem como, relacionando as decisões com outras áreas da empresa, conforme pôde ser observado nos relatórios de gestão apresentados em um seminário final, nos relatórios de tomada de decisão e nas planilhas de apoio à tomada de decisão. O que se pôde observar é que a partir da experiência sensorial passiva, os estudantes passaram à experiencia comportamental ativa, pois, houve alterações significativas no planejamento considerando as rodadas anteriores. Esse processo de evolução pode ser observado nas Figuras 5, 6 e 7. Nelas verificam-se as mudanças na política de precificação, controle gerencial e mudança estratégica (lançamento de um novo produto e participação no mercado - Iphanton [Figura 7]) (Kolb \& Kolb, 2005, Oliveira \& Sauaia, 2011, Sauaia, 2013, Kolb et al., 2014, Kolb, 2015, Oliveira \& Silva, 2019).

Como a experimentação ativa fecha e reconecta o ciclo (recursividade) (Kolb, 2015), como mostra a Figura 5, há indícios de que o aprendizado tenha sido aplicado em circunstâncias similares, pois, ao inicializar a comercialização do produto Alfa no trimestre 3, o produto apresentou margem adequada a realidade da empresa. De maneira similar, ao inicializar a comercialização do produto Iphanton, no trimestre 6, observa-se o mesmo movimento, em que, a margem de contribuição mantém-se igualmente adequada para a cobertura dos custos fixos e geração de lucro. Isso pode evidenciar que o ambiente propiciou a observação do problema, análise teórica e aplicação de intervenção corretiva. Nota-se também que, como descrito na fase da observação reflexiva, o caminho para o desenho de margens adequadas já havia sido percorrido, o que proporcionou êxito ao processo (Sauaia, 2013, Kriz \& Auchter, 2016). A partir do aprendizado, o ciclo reinicia-se tanto no processo de comercialização do produto Alfa, quanto no produto Iphanton (Figura 5) (Kolb, 2015).

Finalizada a análise envolvendo o ciclo de Kolb (2015), passamos a análise do percurso educacional realizado pelo estudante com base no modelo lógico de Kriz e Hense (2006), dentro da métrica "resultados". Nesse sentido, as análises parecem indicar que o ambiente apresenta qualidade satisfatória para o ensino em razão dos efeitos organizacionais percebidos em termos de equilíbrio na política de precificação/custos, traduzidos na correta delimitação da margem de contribuição (Figura 5), aumento do faturamento e lucro líquido (Figura 6), e, liderança em participação no mercado (Figura 7). Isso pode ter ocorrido em razão da completude do ciclo do Kolb no processo de ensino. Nesse sentido, o percurso realizado pelo estudante pode ser observado na Figura 9.

Figura 9 - Esquema do Percurso Educacional Realizado Pelo Participante

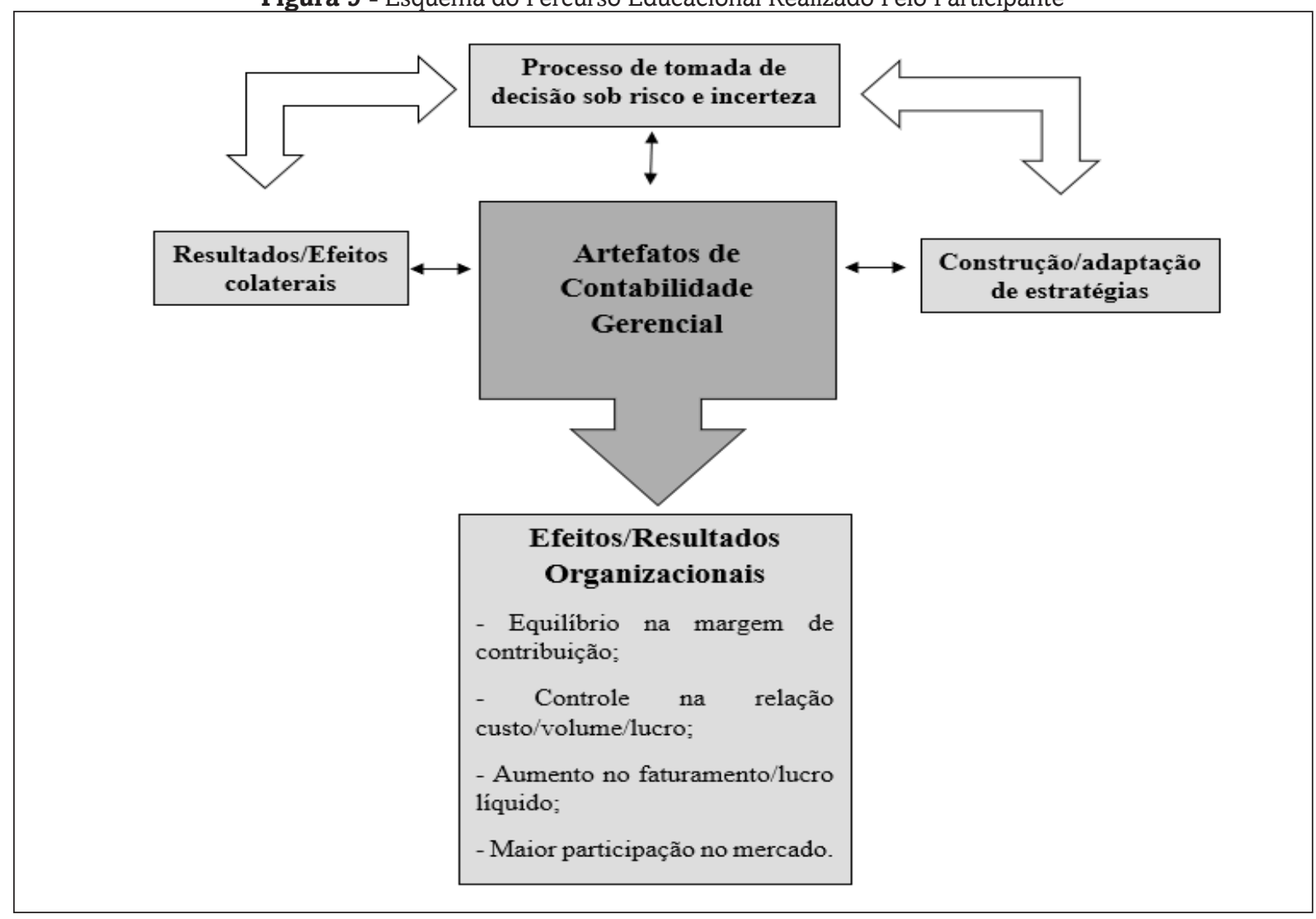

Fonte: dados da pesquisa aliados ao parâmetro resultado do modelo lógico de Kriz e Hense (2006). 
Além disso, observa-se o processo de criação de valor através do uso efetivo dos recursos atrelados ao planejamento estratégico, um artefato moderno, considerando o quarto estágio da evolução dos artefatos de contabilidade gerencial segundo o estudo de Oliveira, Marques e Cintra (2019). A observação de resultados organizacionais positivos, descritos nos relatórios de gestão, coaduna-se com um dos fatores da análise de conteúdo relacionado ao parâmetro resultado no modelo lógico de Kriz e Hense (2006).

Considerando as potencialidades do Laboratório de Gestão, o estudo também teve fulcro na análise da relação entre uma tecnologia de gestão e uma tecnologia educacional. Como explicitado, aliar teoria e prática no ensino gerencial é um problema educacional de mais alta relevância (Keys \& Wolfe, 1990, Oliveira, 2009, Sauaia, 2013; Oliveira \& Silva, 2019). O que se pôde perceber, em especial na aplicação da tecnologia de gestão, trata-se da potencialidade para o processo de ensino mais efetivo em Ciências Contábeis e Administração (Miaguchi \& Sauaia, 2013, Sauaia, 2013, Kriz \& Auchter, 2016).

\section{CONSIDERAÇÕES FINAIS}

Retoma-se a pergunta de pesquisa: quais as potencialidades e limitações do uso de jogos de empresa para o processo de ensino de elementos de contabilidade gerencial? Como potencialidades, nota-se que o ambiente pôde proporcionar os elementos necessários para que o estudante percorresse o ciclo de Kolb (2015). Assim, para além dos métodos convencionais de ensino, o quase-experimento permitiu que o estudante vivenciasse a aplicação de conceitos teóricos de contabilidade gerencial, a resolução de problemas, a demonstração dinâmica das relações de causa e efeito, a interface com outras disciplinas, como a gestão estratégica, e o aprender pela ação.

Para além, quando se observa o parâmetro "resultado" do modelo lógico de Kriz e Hense (2006), no que tange aos efeitos organizacionais visualizados na vivência têm-se a correta delimitação da margem de contribuição, aumento do faturamento e lucro líquido, lançamento de um novo produto e, liderança em participação no mercado. A vivência também permitiu que os estudantes aprendessem com os efeitos colaterais do processo, como o resultado negativo no segundo trimestre, que desencadeou no uso de elementos de contabilidade gerencial. Nesse sentido, há indícios de que o aprendizado tenha sido aplicado para outros produtos (ação proativa e não reativa) em uma atuação sistêmica e antecipatória. Assim, esses achados indicam o percurso educacional realizado pelos estudantes para que fosse possível alcançar determinados resultados organizacionais, positivos ou negativos.

Como uma das limitações da utilização da técnica, percebe-se que nem todos os estudantes apresentam o mesmo nível de envolvimento, dado o estilo de aprendizagem singular. Nesse sentido, embora o ambiente propicie o percurso, não há garantia de que todos os estudantes envolvidos na vivência tenham conseguido completar o ciclo de Kolb (2015). Essa talvez seja uma limitação do método, pois, aparenta haver um limite natural quanto ao controle das atividades pelo professor mediador, seja dentro do grupo ou nos processos de tomada de decisão fora da sala de aula (quem fez o que). De todo modo, a principal limitação do uso de jogos de empresa para o ensino de artefatos de contabilidade gerencial, encontrada nesse estudo, aparenta estar atrelado à identificação da atuação de cada estudante no percurso do ciclo de Kolb, pois, por vezes, esse torna-se um processo autônomo mediado pela própria vivência. Associar a técnica com modelos convencionais de ensino e avaliação podem apresentar-se como alternativa. Outro fator limitante repousa sobre o fato de que os resultados organizacionais positivos ou negativos nem sempre podem expressar aprendizagem e podem ser influenciados por outros fatores (Oliveira \& Sauaia, 2011).

Como principal contribuição, o estudo apresenta um método ativo para o ensino/aprendizagem com a potencialidade de complementar os métodos convencionais de ensino utilizados em Ciências Contábeis e Administração, em especial, fornecendo ao ambiente de aprendizagem a possibilidade de visualização da aplicação prática de uma teoria e a resolução de problemas reais. Esses achados coadunam-se com outros estudos (Keys \& Wolfe, 1990, Kolb \& Kolb, 2005 , Faria et al., 2009, Oliveira, 2009, Ben-Zvi, 2010, Stainton, Johnson \& Borodzicz, 2010, Sauaia, 2013, Ben-Zvi, \& Carton, 2014, Kallás \& Sauaia, 2014, Kriz \& Auchter, 2016, Silva, Oliveira, \& Leal, 2016, Oliveira \& Silva, 2019).

Além disso, o artigo demonstra como o ambiente do jogo de empresas pode criar contextos que permitam ao estudante completar o percurso do ciclo da aprendizagem vivencial de Kolb, de tal sorte que, o estudo pode ser uma ferramenta para auxiliar professores na compreensão e posterior aplicação da técnica. Outra contribuição está na aparente associação entre a completude do cliclo de Kolb e o modelo lógico de Kriz e Hense (Kriz \& Auchter, 2016).

Ainda assim, este estudo tem limitações que abarcam as análises documentais provenientes da vivência, pois, essa foi a única fonte de dados. Também, não foi realizado estudo comparativo em profundidade com outros grupos que tenham participado do jogo. Outra limitação, é que o estudo apresentou o que foi feito, mas não apresentou como os estudantes construíram as soluções, o que também, muito provavelmente, confirmaria a teoria. Todas essas lacunas podem ser abarcadas por estudos futuros. Esses mesmos estudos podem se debruçar sobre as implicações estratégicas do uso de artefatos de contabilidade gerencial nos resultados da organização, aliando as impressões do professor mediador como ator participante desse processo. 


\section{REFERÊNCIAS}

Bardin, L. (2013). Análise de conteúdo. Lisboa: Edições 70.

Almada, M. A. S., de Souza, P. C., \& Laia, A. O. (2016). Aplicação do custeio variável e análise custo-volume-lucro numa indústria de ração animal: um estudo de caso. Custos e Agronegócios on-line, 12(4), 72-89.

Apesteguia, J., Azmat, G., \& Iriberri, N. (2012). The impact of gender composition on team performance and decision making: Evidence from the field. Management Science, 58(1), 78-93. doi: doi.org/10.1287/mnsc.1110.1348

Beal, D. J., Cohen, R. R., Burke, M. J., \& McLendon, C. L. (2003). Cohesion and performance in groups: a meta-analytic clarification of construct relations. Journal of applied psychology, 88(6), 989-1004. doi: dx.doi.org/10.1037/0021-9010.88.6.989

Ben-Zvi, T. (2010). The efficacy of business simulation games in creating Decision Support Systems: An experimental investigation. Decision Support Systems, 49(1), 61-69. doi: doi.org/10.1016/j.dss.2010.01.002

Ben-Zvi, T., \& Carton, T. C. (2014, January). Applying Bloom's Revised Taxonomy in Business Games. In Developments in Business Simulation and Experiential Learning: Proceedings of the Annual ABSEL conference, 35.

Beuren, I. M., Souza, L. R. B., \& Feuser, H. D. O. L. (2017). Implicações de um Centro de Serviços Compartilhados na Contabilidade Gerencial: Uma Abordagem Institucional. REAd-Revista Eletrônica de Administração, 23(3), 32-61. doi: 10.1590/1413-2311.162.61627

Braga, R. (1989). Fundamentos e técnicas de administração financeira. São Paulo: Atlas.

Cooper, D. R., \& Schindler, P. S. (2011). Métodos de pesquisa em administração. (10. ed.). Porto Alegre: Bookman.

Cruz, V. L., Coutinho, A. D. Q. H., Lagioia, U. C. T., Morais, R. S., Peixoto, E. P. A., Meireles, J. M. S. (2014). O ensino de contabilidade gerencial e sua aplicação na prática: um estudo sobre as ferramentas gerenciais utilizadas pelos prestadores de serviços contábeis em um estado brasileiro. In Anais do Congresso Brasileiro de Custos-ABC, 21.

Dias, I. P. (1967). Algumas observações sobre a margem de contribuição. Revista de Administração de Empresas, 7(24), 79-101. doi: dx.doi.org/10.1590/S0034-75901967000300003

Faria, A. J., Hutchinson, D., Wellington, W. J., \& Gold, S. (2009). Developments in business gaming: A review of the past 40 years. Simulation \& Gaming, 40(4), 464-487. doi: 10.1177/1046878108327585

Faria, P. M. O., \& Leal, E. A. (2016). Análise da temática Contabilidade Gerencial na formação em Ciências Contábeis de IES mineiras à luz do Currículo Mundial e da Proposta Nacional do CFC/FB. Revista de Educação e Pesquisa em Contabilidade (REPeC), 10(2). doi: $10.17524 /$ repec.v10i2.1302

Ferreira, L. M. L., Wanzeler, M. S., Melo, R., Oliveira, S., \& Oliveira, A. B. (2014). Cost Management in Agribusiness: study profitability scenarios of Integrated System vs. Independent System for a Poultry Producer. Independent Journal of Management \& Production, 5(2), 493-510. doi: 10.14807/ijmp.v5i2.160

Fuksa, D., Trzaskuś-Żak, B., Gałaś, Z., \& Utrata, A. (2017). An evaluation of practical applicability of multi-assortment production break-even analysis based on mining companies. Archives of Mining Sciences, 62(1), 33-44. doi: doi.org/10.1515/amsc-2017-0003

Gerhardt, T. E., \& Silveira, D. T. (2009). Metodologia de Pesquisa Cientifica. Porto Alegre: Editora da URFGS.

Hernandes Junior, M.(2016). A utilização do custeio variável para a gestão de resultados: um estudo baseado em empresas que aderiram aos sites de compr $\neq$ as coletivas. Revista Mineira de Contabilidade, 17(2), 42-55

Hinterhuber, A. (2004). Towards value-based pricing-An integrative framework for decision making. Industrial Marketing Management, 33(8), 765-778. doi: doi.org/10.1016/j.indmarman.2003.10.006

Horngren, C. T. (2000). Introdução à contabilidade gerencial (7a reim.). Rio de Janeiro: LTC.

Horngren, C. T., Sundem, G. L., \& Stratton, W. O. (2004). Contabilidade gerencial. (12a edição). São Paulo: Person Education.

Kallás, D., \& Sauaia, A. C. A. (2014, February). Implementation and impacts of the Balanced Scorecard: An experiment with business games. In Developments in Business Simulation and Experiential Learning: Proceedings of the Annual ABSEL Conference (Vol. 31).

Keys, B., \& Wolfe, J. (1990). The role of management games and simulations in education and research. Journal of Management, 16(2), 307-336. doi: 10.1177/014920639001600205

Kleijnen, J. P., \& Smits, M. T. (2003). Performance metrics in supply chain management. Journal of the operational research society, 54(5), 507-514. doi: doi.org/10.1057/palgrave.jors.2601539 tion.

Kolb, A. D. (2015). Experiential learning: experience as the source of learning and development. (2a ed.) New Jersey: Pearson Educa-

Kolb, A. Y., \& Kolb, D. A. (2005). Learning styles and learning spaces: Enhancing experiential learning in higher education. Academy of Management Learning \& Education, 4(2), 193-212. doi: 10.5465/AMLE.2005.17268566

Kolb, A. Y., Kolb, D. A., Passarelli, A., \& Sharma, G. (2014). On becoming an experiential educator: The educator role profile. Simulation \& Gaming, 45(2), 204-234. doi: doi.org/10.1177/1046878114534383

Kriz, W. C., \& Hense, J. U. (2006). Theory-oriented evaluation for the design of and research in gaming and simulation. Simulation \& Gaming, 37(2), 268-283. doi: doi.org/10.1177/1046878106287950

Kriz, W. C., \& Auchter, E. (2016). 10 Years of Evaluation Research Into Gaming Simulation for German Entrepreneurship and a New Study on Its Long-Term Effects. Simulation \& Gaming, 47(2), 179-205. doi: 10.1177/1046878116633972 
Laboratório de Gestão Organizacional Simulada - LAGOS. (2017). Manual do participante: simulador organizacional Grego Mix [Mimeo]. Universidade Federal Fluminense, Volta Redonda, Rio de Janeiro.

Lavarda, C. E. F., Panucci-Filho, L., \& Michels, A. (2017). Ensino de Contabilidade Gerencial: o "gap” entre a formação e prática ainda persiste? Revista de Contabilidade da UFBA, 11(1), 38-55. doi: 10.9771/rc-ufba.v11i1.18297

Malhotra, N. (2001). Pesquisa de marketing: uma orientação aplicada. (3a ed.). Porto Alegre: Bookman.

Miranda, C. S., Riccio, E. L., \& Miranda, R. A. M. (2013). O ensino da contabilidade gerencial no Brasil: uma avaliação de grades curriculares e literatura didática. Revista Contabilidade e Controladoria, 5(2), 25-42. doi: dx.doi.org/10.5380/rcc.v5i2.29980

Miaguchi, Y., \& Sauaia, A. C. A. Análise custo-volume-lucro no auxílio à tomada de decisão. In: Sauaia. A. C. A. (2013). Laboratório de gestão: simulador organizacional, jogo de empresa e pesquisa aplicada. (3a ed., Cap. 9, p. 137-172). Barueri: Manole.

Muller, S. H., Schuster, H. A., \& Zonatto, V. C. D. S. (2017). Oportunidades de melhoria no ensino de disciplinas que abrangem conteúdos de Custos: uma análise com base na percepção de discentes. Administração: Ensino e Pesquisa, 18(2), 301-315. doi: 10.13058/ raep.2017.v18n2.535

Oliveira, M. A. (2009). Implantando o Laboratório de Gestão: um programa integrado de educação gerencial e pesquisa em administração. Tese de doutorado, Universidade de São Paulo, SP, Brasil. doi: 10.11606/T.12.2009.tde-18122009-094527

Oliveira, M. A. (2017). Gestores de avental branco? Ambientes experimentais na educação gerencial. REVISTA LAGOS, 6(1), 1-4. Recuperado em 12 outubro, 2018, de ww.revistalagos.uff.br/index.php/lagos/article/download/258/116

Oliveira, M. A., \& Sauaia, A. C. A. (2011). Impressão docente para aprendizagem vivencial: um estudo dos benefícios dos jogos de empresas. Administração: Ensino e Pesquisa, 12(3), 355-391. doi: 10.13058/raep.2011.v12n3.159

Oliveira, M. A, \& Silva, S. O. (Org.). (2019). Gestão estratégica na prática: um laboratório para gestores. Curitiba: CRV.

Oliveira, T. C., Marques, M. L., \& Cintra, Y. C. (2019). Artefatos de contabilidade gerencial: um estudo em cursos de graduação em ciências contábeis da região sudeste do Brasil. Revista Mineira de Contabilidade, 20(2), 31-42. doi: doi.org/10.21714/2446-9114RMC2019v20n2t03

Paula, A. P. P. D., \& Rodrigues, M. A. (2006). Pedagogia crítica no ensino da administração: desafios e possibilidades. Revista de Administração de Empresas, 46(SPE), 10-22. doi: dx.doi.org/10.1590/S0034-75902006000500001

Perez, J. H. Jr., Oliveira, L. M., \& Costa, R. G. (2011). Gestão estratégica de custos. São Paulo: Atlas.

Redivo, R. B. (2004). Considerações sobre o cálculo da margem de contribuição: uma proposta para inclusão do custo de reposição e do custo de oportunidade. Revista de Ciências da Administração, 6(11), 87-102. doi: dx.doi.org/10.5007/\%25x

Ribeiro, R. P., Sauaia, A. C. A., \& Fouto, N. M. M. D. (2014). Custos e economias de escala em um jogo de empresas. RACE-Revista de Administração, Contabilidade e Economia, 13(2), 663-688.

Ribeiro, R. P., Sauaia, A. C. A., Mello, A., \& Torres, A. S. Jr. (2015). Praticando Gestão de Operações em um Laboratório de Gestão. RAM. Revista de Administração Mackenzie, 16(4), 43-76. doi: 10.1590/1678-69712015/administracao.v16n4p43-76.

Santos, R. (2003). “ Jogos de empresas” aplicados ao processo de ensino e aprendizagem de contabilidade. Revista Contabilidade \& Finanças, 14(31), 78-95. doi: 10.1590/S1519-70772003000100006

Santos, L. A., Marion, J. C., \& Kettle, W. M. (2014). Gestão estratégica de custos: um enfoque gerencial utilizando análise CVL na produção de leite da fazenda UNASP EC. Custos e Agronegócio online, 10(3), 24-37.

Sauaia A. C. A. (2013). Laboratório de gestão: simulador organizacional, jogo de empresa e pesquisa aplicada. (3a ed.). Barueri: Manole.

Sauaia, A. C. A., \& Oliveira, M. A. (2011). Decomposição do Desempenho Organizacional em um Jogo de Empresas. Revista Eletrônica de Estratégia \& Negócios, 4(1), 158-182. doi: dx.doi.org/10.19177/reen.v4e12011158-182

Silva, E. L. \& Menezes, E. M. (2005). Metodologia da pesquisa e elaboração de dissertação (4a ed.). Florianópolis: UFSC.

Silva, S. S., Oliveira, M. A., \& Leal C. Jr. (2016). Modelo de previsão de vendas em jogos de empresas: potencializando a prática dos gestores. Revista Pensamento Contemporâneo em Administração, 10(2), 50-64. doi: dx.doi.org/10.12712/rpca.v10i2.578

Silva, S. S., Oliveira, M. A., \& Motta, G. S. (2013). Jogos de empresas e método do caso: contribuições ao processo de ensino e aprendizagem em administração. Administração: Ensino e Pesquisa, 14(4), 677-705. doi: 10.13058/raep.2013.v14n4.52

Stainton, A. J., Johnson, J. E., \& Borodzicz, E. P. (2010). Educational validity of business gaming simulation: a research methodology framework. Simulation \& Gaming, 41(5), 705-723. doi: doi.org/10.1177/1046878109353467.

Vergara, S.C. (2009). Projetos e relatórios de pesquisa em administração (10a ed.) São Paulo: Atlas.

Wernke, R., \& Lembeck, M. (2008). Aplicação da análise custo/volume/lucro em pequena indústria de laticínios. Revista Catarinense da Ciência Contábil, 7(21), 53-70. doi: dx. doi. org/10.16930/2237-7662/rccc 